Rashid G. Alakbarov

DOI: $10.25045 /$ jpis.v07.i1.02

Institute of Information Technology of ANAS, Baku, Azerbaijan

rashid@iit.ab.az

\title{
AZSCIENCENET SCIENCE-COMPUTER NETWORK: STAGES OF DEVELOPMENT, INTERNET SERVICES AND PROSPECTS
}

The article is devoted to the provision of wide-range Internet services to ANAS institutes and organizations in the realization of scientific research, scientific-practical and education issues of AzScienceNet science-computer network. Wi-Fi, Eduroam, Cloud Computing, Hosting, e-mail, distant education and etc. services provided to ANAS employees by AzScienceNet are specified in the article. AzScienceNet network is considered as one of the primary goals associated with the development of information society in Azerbaijan and it supports all the measures adopted in this direction.

Keywords: information society, e-science, AzScienceNet, Internet services, cloud technologies, eduroam, cloud computing, information security.

\section{Introduction}

The integration to the world community and the informatization processes carried out in the country poses new goals and duties in the sphere of scientific activity, along with other fields. These tasks contemplate the efficiency increase of management and conducted scientific studies in scientific institutions, the linking and direction of their activities, and the application of information-communication technologies (ICT) of scientific activity with the purpose of the integration of Azerbaijan science into scientific environment.

Several requirements posed in the presidential decree related to approval of "The National Strategy on Development of Science in the Republic of Azerbaijan in 2009-2015 years" approved on 4th May 2009 and "The State Program" on the realization of this Strategy have necessitated the development and realization issues of "e-science" concept within the framework of reforms in science in the country. This matter is being realized on AzScienceNet science-computer network platform of the Institute of Information Technologies (IIT) of ANAS. AzScienceNet provides the joint operation of scientific institutions and organizations engaged in scientific activity by establishing the necessary information-communication infrastructure, the access to scientifictechnical information and to computation resources via high-speed Internet network.

AzScienceNet science-computer network closely supports the measures proposed by "Azerbaijan 2020: the vision to future" development concept approved by the decree dated 29 December 2012, "The National Strategy on development of science in Republic of Azerbaijan in 2009-2015 years" approved by the decree dated $4^{\text {th }}$ May 2009 and "The National Strategy on development of information society in Republic of Azerbaijan for 2014-2020 years" approved by the decree dated $2^{\text {nd }}$ April 2014. Hence, important tasks such as the strengthening information maintenance of science, the application of ICT in scientific activity field and the formation of electronic science have been specified in those concepts and strategies.

\section{The stages of Development of AzScienceNet network}

AzScienceNet science-computer network plays a prominent role as a national operator on science and education networks providing the integration of the science of Azerbaijan into world science, by providing high-level Internet services to ANAS scientific institutions and organizations in the realization of tasks emanating from the above mentioned respective concepts and strategies. AzScienceNet science-computer network, created on the basis of ANAS corporate network, provides wide-range Internet services to ANAS institutes and organizations in the resolution of scientific-research, scientific-practical and training issues. 
The primary goal of AzScienceNet formed towards the building of information society in the country is the provision of contemporary network services, necessary for the solution of scientificresearch works, also scientific-practical and training issues tackled by ANAS institutes and organizations.

It must be noted that a sufficient level of scientific potential and practice is present in the country for the realization of specified tasks. It does not only provide the access to scientifictechnical information and computation resources via high-speed Internet network, but also facilitates the joint operations.

AzScienceNet coverage includes ANAS Presidium, ANAS institutions and organizations, ANAS Nakhchivan and Ganja branches, and Lankaran and Sheki Regional Scientific Centers. ANAS is a government institution conducting and coordinating the official scientific-technical policy of the government, the management of scientific activity, as well as the scientific studies and investigations. The realization of these prominent and complex issues emerges several tasks for respective organizations.

The establishment of AzScience dates back to 1980's. During those years, the Data Transmission Network covering Republican Computation Centers (Azerbaijan State Plan Committee, "Azerenerji" Industrial Association) was established, based on x.25 technology of multi-terminal computational system of AMS (Automated Management Systems) center as the predecessor of IIT of ANAS (Figure 1).

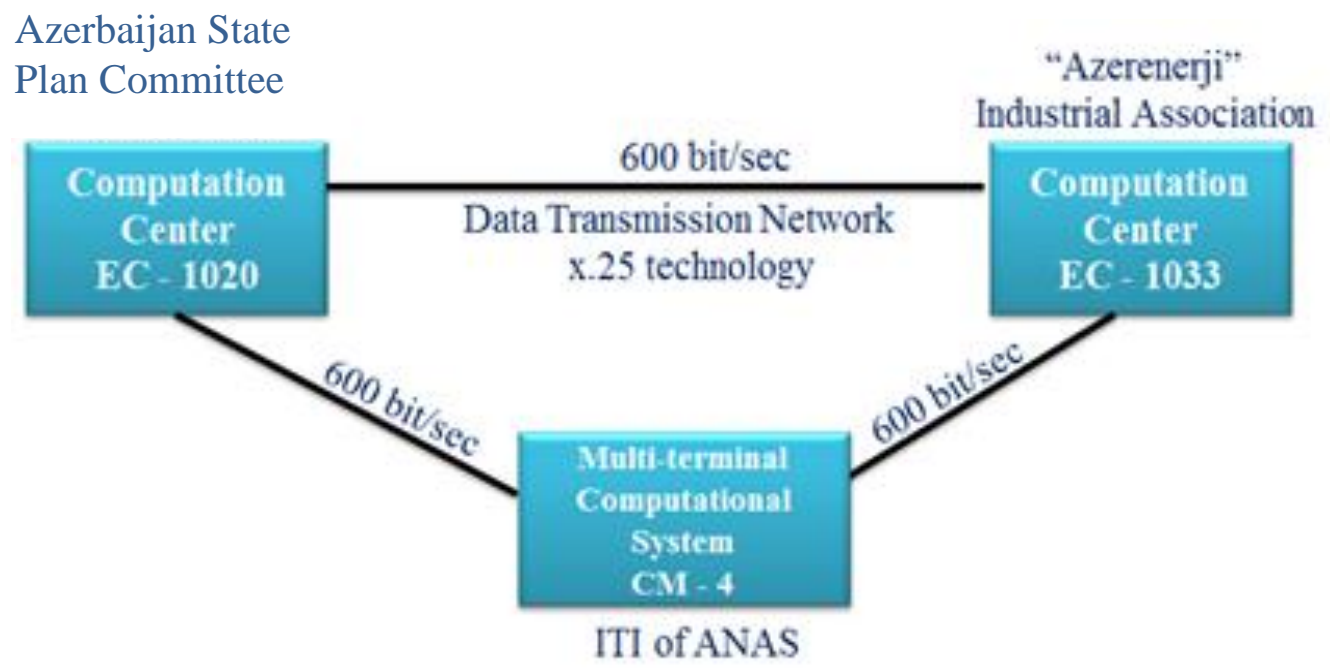

Figure 1. Data Transmission Network based on x.25 technology.

The AMS department of AAS has been appointed as a primary executor of the European Academic and Research Computer Networks (EARN) by the Order of the Presidium of USSR Academy of Sciences and had established Azerbaijan station of EARN in 1991. Besides, the organization has established the Azerbaijan Station of International Electronic Post (AS IEP) by joining "Sovam Teleport" network according to the direction of the Cabinet of Ministers of Republic of Azerbaijan and the Order of the Presidium of AAS. This electronic post service has facilitated the access to information in "Sovam Teleport", "EARN", "BITNET", "RELCOM", «IASNET» and etc. International Computer Networks for entities and organizations of Presidium of AAS and several ministries and state entities.

AS IEP has become the main station of the Republican Information Computation Network (RICN) in Azerbaijan and maintained the connection of local networks of the main building of AAS Presidium and IIT of ANAS with International Computer Networks by comprising those. With comprehensive financial support of Turkish government and BP oil company, IIT of ANAS has purchased the telecommunication equipment, server and service computers complying with 
the level of technical features of the time in 1993, and for the first time, has established the first Internet junction of Azerbaijan in AAS main building. At the time, the internet speed provided by Turkey was reaching $9600 \mathrm{bit} / \mathrm{sec} .14400 \mathrm{bit} / \mathrm{sec}$ speed provided by the Russian Academy of Sciences has been added to that speed thereafter.

As a result of the continuous development of technical support and software and the increase of Internet connection channel speed, the Internet connection was provided for all institutions and organization located in the Academy campus. Local computer networks of institutes, mutually connected via the first Internet junction of Azerbaijan, comprised more than 50 computers. More than 20 subscribers located farther from the Academy campus have connected to this station with commuted phone line in Dial-Up regime.

Moreover, in order to meet the increasing Internet access requirements of ANAS Presidium and closely located state organizations, the Second Internet junction of Azerbaijan has been established in ANAS Presidium building in 1995. As a result of the telephone line directly separated among those stations, Internet network with the largest infrastructure has started to operate in the Republic.

Subsequently, the first junction has encompassed ANAS main building, all institutes located in the Academy campus and its vicinity, whereas the second junction has covered ANAS Presidium, its institutes and departments. The far-located institutes to ANAS and several state organizations have been connected to both junctions with phone lines.

The institutes, located in the main building of ANAS and covered by the first junction, were connected to the main building of ANAS by fiber optic cables. Local networks with Ethernet architecture was established within each institution.

The following development stage of ANAS Internet network had started with the assignment of realization of "Virtual Silk Road" project proposed by the UN Scientific Committee to ANAS.

The "Virtual Silk Road" project envisaged the connection to Internet network of three Caucasus countries - Azerbaijan, Armenia, Georgia, and five Central Asian countries - Uzbekistan, Turkmenistan, Kyrgyz Republic, Kazakhstan and Tajikistan, with the most advanced satellite technology and thus, the establishment of "Virtual Silk Road" project..

The primary goal of this project is the creation of necessary opportunities for solving socioeconomic and other problems emerged in strategical fields such as science and education, alongside with the substantial increase of the information exchange among academic societies of the above mentioned countries. On this purpose, the assembly of satellite antenna and the network equipment has been planned in each of eight countries (Figure 2). This equipment was considered to be connected to Network operation center located in Hamburg, Germany via EUROASIASAT satellite station via artificial satellite as shown in Figure 2.

In 2003, the opening ceremony of VSAT type aboveground satellite-communication equipment start-up has taken place in the Institute of Information Technologies of ANAS, which has been delivered to the republic within the framework of "Virtual Silk Road" project by NATO Scientific Committee. Secretary general of NATO, lord George Robertson, councils of foreign countries, prominent scientists of the republic and the representatives of various ministries, science and education institutions have participated in the ceremony. A videoconference has been held between the Network operation center located in IIT of ANAS and the NATO Network operation network located in Hamburg, Germany during the ceremony. 

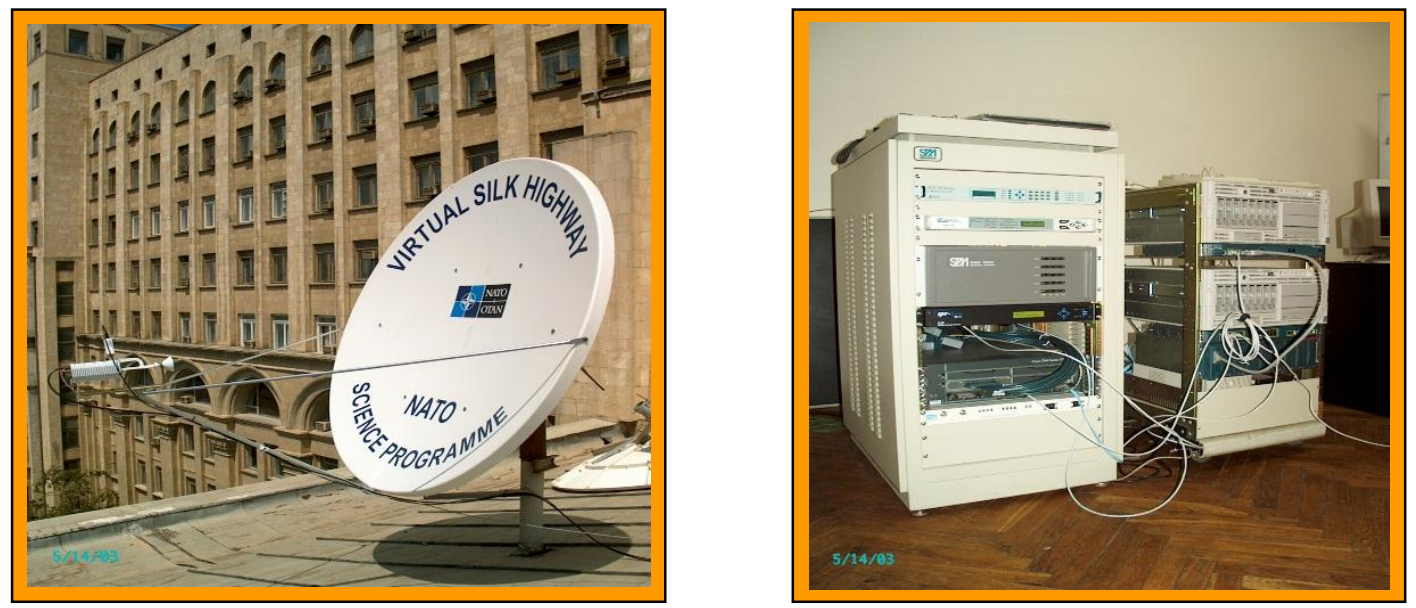

Figure 2. The Equipment assembled according to "Virtual Silk Road" project

It is to be noted that the information downlink speed from Internet via "Virtual Silk Road" project had reached $3 \mathrm{Mbps}$ and the information transmission speed had been $512 \mathrm{Kbps}$ until December 2005.

Currently, the socio-economic development of Republic of Azerbaijan has facilitated the provision of AzScienceNet science-computer network infrastructure with new equipment and the high-speed connection to international computer network.

It must be mentioned that. in 2009, the IIT of ANAS has been assigned by ANAS Presidium to establish a new junction of AzScienceNet science-computer network. The working group formed in the Institute for this purpose has carried out intensive research work. By taking conducted research and practical studies in this field as the basis, the measures have started to be carried out in association with the establishment of new Data processing center of AzScienceNet science-computer network. The new junction of AzScienceNet science-computer network has been put into service in 2010 (Figure 3).
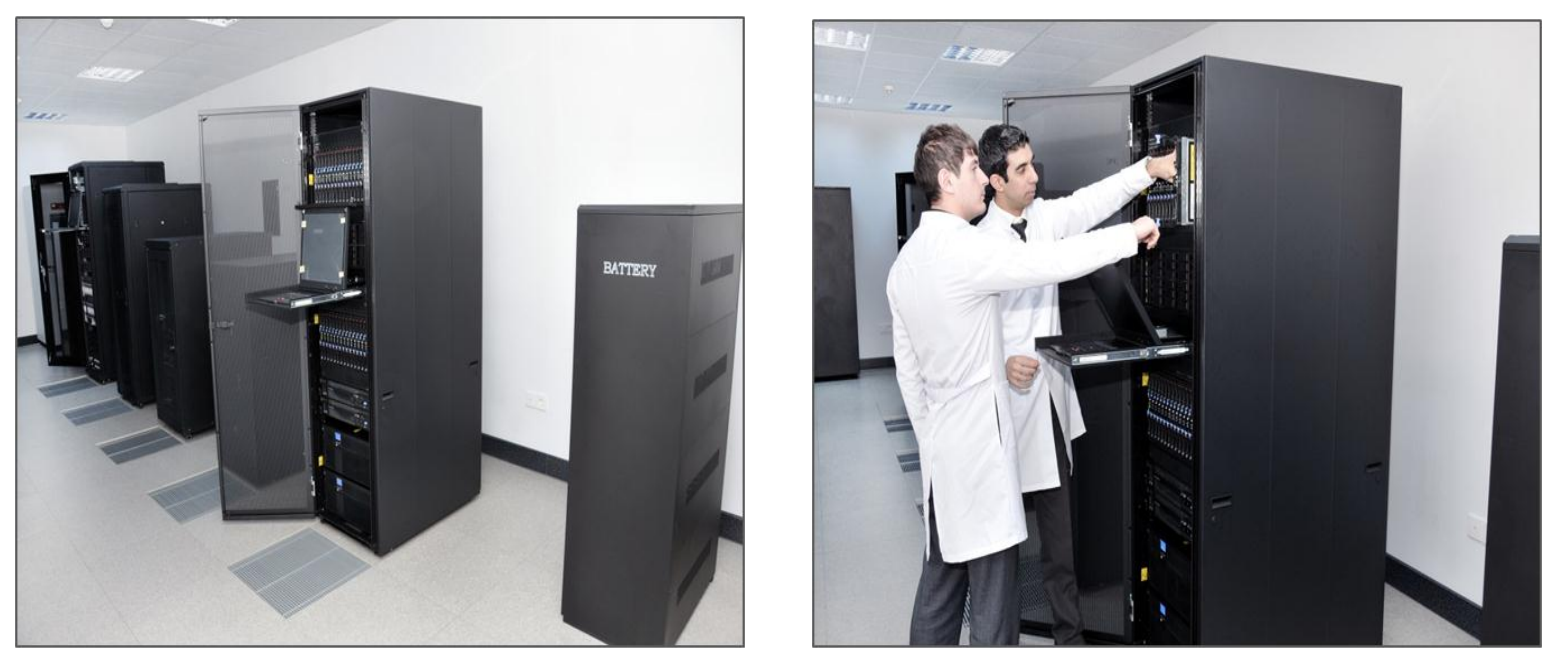

Figure 3. The new center of AzScienceNet science-computer network

The Center located in the building of the Institute of Information Technologies of ANAS has been established based on the telecommunications and server equipment of Cisco and HP companies. The newly established center has gained access to Internet by connecting to Delta Telekom with optic connection channels. The Internet access speed of AzScienceNet science- 
computer network has reached $130 \mathrm{Mb} / \mathrm{sec}$. At present, the technical features of AzScienceNet science-computer network and Data Center are as following:

- The number of individual computers connected to AzScienceNet network - 4000 units;

- Internet connection speed - $270 \mathrm{Mbit} / \mathrm{s}$;

- Computation power - 14 Tflops.;

- The volume of bulk memory - 200 Tbytes.

The primary purpose of the Internet Center is the provision of high-speed, secure, 24-hour Internet access to global network for "AzScienceNet" science-computer network users. At the same time, in accordance with the requirements of the above mentioned state programs, the enhancement of AzScienceNet science-computer network infrastructure, the reliable establishment of security and monitoring systems, the application of open grid, cloud computing and eduroam services, and the organization of video conference system facilitate the realization of complex actions towards the integration with corresponding scientific network entities performing at international level and other countries. The provision of "AzScienceNet" sciencecomputer network with new telecommunications and server equipment, and the realization of various Internet services on the basis of those have accelerated the integration of this network into various network infrastructures of the world and Europe, in particular.

The membership of AzScienceNet science-computer network to TERENA (Trans European Research and Education Networking Association-Trans) has been agreed in General Assembly in Vilnius, Lithuania on 3-4 ${ }^{\text {th }}$ June, 2010. Thirty nine countries became members of TERENA. Azerbaijan is among those countries. Alongside with Azerbaijan, Latvia, Estonia, Moldova and Belarus are also the members of the mentioned organization among CIS countries. ANAS has carried out a significant step towards the integration of scientific-research and education network of Azerbaijan into corresponding network infrastructure of Europe. Azerbaijan is represented by the IIT ANAS in mentioned organization, close cooperative relations exist between them. General Assembly of TERENA is the supreme body of the organization. TERENA encompasses the networks of national academic and other associated organizations in European countries. The primary goal of TERENA is to assist the improvement of international networks' performances used for scientific purposesç considering the interests of member countries in the association.

It is to be mentioned thatç in 2011, the use policy has been developed for the efficient and secure use of AzScienceNet science-computer network resources [2]. The primary purpose of the policy is the purposeful and secure application of AzScienceNet science-computer network resources in the solution of scientific-research, scientific-practical and education issues carried out in scientific institutions of Azerbaijan.

\section{The services of AzScienceNet science-computer network}

AzScienceNet science-computer network provides the following Internet services to users:

- electronic mail service;

- hosting services;

- monitoring and information security services;

- AzScienceCERT service;

- electronic library service;

- distant education service;

- Cloud Computing service;

- eduroam service;

A mail-server is set up for e-mail service of AzScienceNet science-computer network in the Internet center of the IIT of ANAS. This mail-server provides services to AzScienceNet sciencecomputer network users. CommuniGate Pro software is applied for creating mailboxes for e-mail users and making changes in Mail-server. In general, 1500 users are benefitting from e-mail services. Each of them are assigned 1Gbyte mailbox in mail-server. 
At present, the web-sites of more than 30 organizations are located in hosting server.

Monitoring and information security service provides the network activity of monitoring system of AzScienceNet science-computer network.

The monitoring system carries out the following issues [3]:

- maintenance of network security;

- control over the state of network;

- optimal utilization of allowed throughout bar;

- monitoring of user activity;

- optimization of network equipment parameters;

- detection of network failures;

- data collection for decision-making related to the organization of network activity.

AzScienceNet science-computer network prepares various reports regarding the monitoring of activity of network users:

- Report on IP-addresses;

- Report on data type;

- Report on host categories;

- Report on countries;

- Report on days;

- Report on weekdays;

- Report on day hours;

- Report on web-sites.

AzScienceCERT service is a group responding to information security incidents in AzScienceNet science-computer network. The main purpose of AzScienceCERT is the maintenance of management of information security risks at AzScienceNet science-computer network at an allowed level. In accordance with this purpose, AzScienceCERT carries out such issues as the detection, prevention and user apprising with regards to the actions intending to violate information security.

AzScienceCERT service conducts the collection, storage and the analysis of statistical data related to the expansion of malicious programs and network threats in AzScienceNet sciencecomputer network.

In order to carry out the targeted tasks, AzScienceCERT establishes mutual connections with other similar groups operating in Azerbaijan, government bodies, international groups, engaged in the processing of information security incidents and other organizations operating in the information security field. Therefore, AzScienceCert team has been registered by European CERTs' Trusted Introducer (TI) service in 2010. TI service is active within Trans-Europe Research and Education Network Association (TERENA). Its main goal is creating trust among CERT centers of European countries. TI includes new entities into trust network, and plays a role of the reliable third party. TI service is engaged in registration, accreditation and certification of CERTs [4, 5].

The infrastructure of the IIT electronic library service is established on the basis of AzScienceNet network. The established Intellectual Information Service System is developed for the purpose of provision of operative information services oriented to user request in both online regime and electronic library base. The system functions are realized in several modules and grouped under "Information", "Electronic catalogue", "Electronic resources", "Electronic libraries", "Administrator menu" sections in the menu.

Multifaceted activities are being implemented regarding the development and application of new training forms, including distant education and enhanced opportunities of interactive training. Measures are being carried out in stages towards the establishment of distant education centers, based on the advanced technologies in all science and education institutions of the Republic. 
Distant education service is established based on AzScienceNet science-computer network in the IIT of ANAS. The distant education center is established using the equipment of Polycom company possessing enhanced facilities. This service, first, has been used by doctoral students and degree candidates of Nakhchivan State University (NSU). In 2014, the second Distant Education Center has been established in ANAS Ganja branch; doctoral students and degree candidates of science and education institutions located in Ganja and neighboring areas already benefit from distant education. In future, the establishment of Distant Education Center of the Institute in Mingachevir, Sheki and Lankaran is planned in future.

Cloud computing service was established in 2014. The application of Cloud Computing services is economically more efficient. Cloud Computing service provides users with the computation and memory resources by carrying out the clustering and virtualization of computation and memory resources of data processing center with the help of communication technologies $[6,7]$. The employees of ANAS institutes and organizations employ the computation and memory resources of the IIT data processing center in order to use Cloud Computing system services. Firstly, this system is constituted of cluster-type computation system of 512 virtual processor (multi-core processor) and 200 Tbytes of memory. The data memorization block is comprised of 200 Tbytes SAN technology-based memory massive. Users are connected to the center with high-speed connection channel. The established system will allow the more efficient use of computation and memory resources.

In 2010, Eduroam (education roaming) service was established. Eduroam services facilitate the connection to global Internet network for users from any corner of the world [8]. The following measures have been taken in order to apply Eduroam service in Azerbaijan, and connect the country to the worldwide eduroam network and to introduce it:

- National Eduroam server software has been developed and user registry system has been established;

- Wireless $W i-F i$ access point equipment has been set up.

Azerbaijan National Eduroam server is located in AzScienceNet science-computer network, it carries out republic-wide National Operator function and has been registered in European Eduroam Confederation organization on 11 November 2011. At present, this service is created in 6 ANAS institutes.

AzScienceNet network provides Internet services in Education-Innovation Center (EIC), which was established in 2003, and is one of the structural departments of the IIT. Network infrastructure in EIC is created on the basis of AzScienceNet science-computer network. EIC is closely engaged in measures concerned with the formation of information society and the establishment of electronic government in Azerbaijan. As known, the main purpose in establishment electronic government is growing computer literacy and information culture in all members of the society. The activity of EIC is constructed in the direction of realization of this purpose:

- Teaching "Informatics" subject to all doctoral and $\mathrm{PhD}$ students, and adoption of candidacy minimum examinations in accordance with the Resolutions dated 25 October 2002 and 16 December 2002 of Higher Attestation Commission under the President of Republic of Azerbaijan;

- The organization of Information Technologies (IT) courses in different directions;

- Knowledge certification in IT sphere.

During 2003-2004 years, around 14 thousand doctoral students and degree candidates have participated in "Informatics" courses and have taken candidacy examinations. 


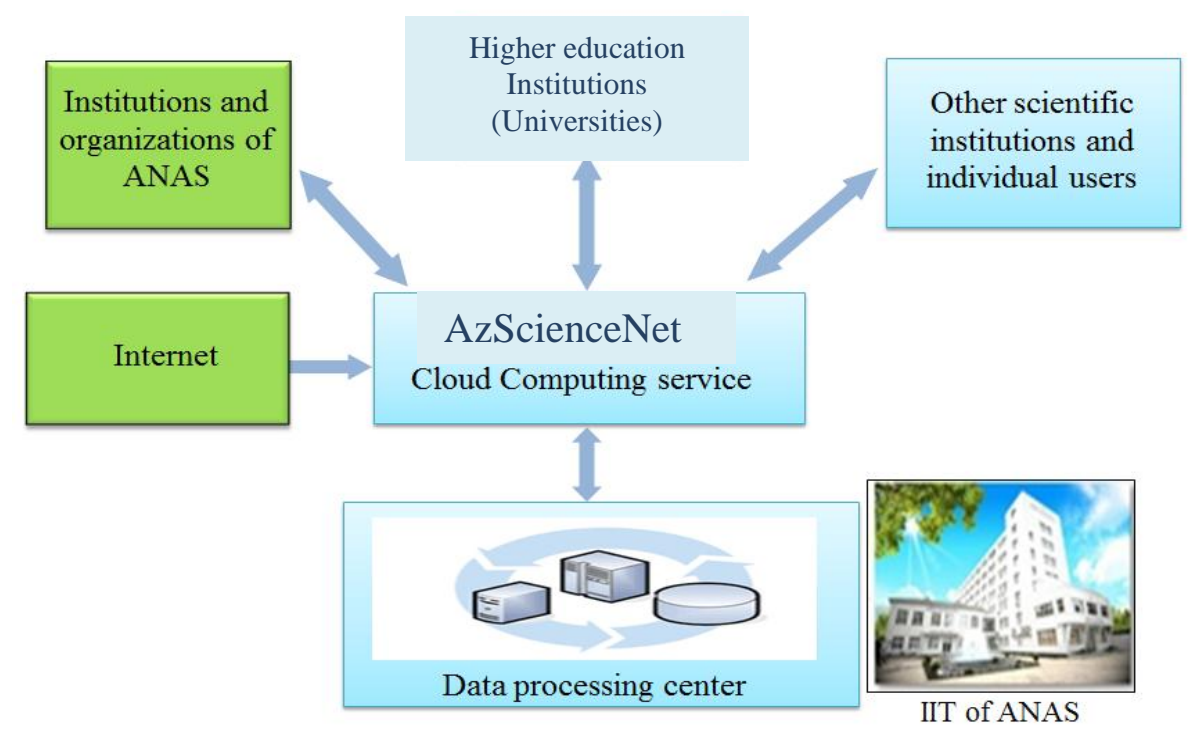

Figure 4. Cloud Computing service

In 2014, online TV broadcasting service has been created on network over the Internet. With the help of this service, the conferences, events and etc. held in ANAS institutes and organizations can be streamed online over the Internet. The First Congress of Azerbaijan Scientists held on 18 December 2014 was streamed live via Internet. The Congress had been viewed by approximately thousand Azerbaijanis residing abroad.

The organization of "Hot line" service on network. This service is activated by AzScienceNet science-computer network users addressing their complaints (via e-mail, phone or web-site), regarding the problems emerged in the network, to the operator of the 24/7 active Call Center. After the operator redirects the information to center administrator, the latter quickly eliminates the emerged problem, together with technical team. The established system carries out the processing, control and analysis of requests incoming from users.

\section{Development prospects of AzScienceNet science-computer network}

AzScienceNet science-computer network is a network platform and main infrastructure of "E-science", a project of "Electronic Azerbaijan" State Program (SP) carried out in the country. "E-science" plays a prominent role in organization and development of scientific activity in accordance with contemporary requirements, enhancement of scientific management and the formation of national scientific information space by using ICT facilities. "E-science" targets the mutual link among scientific organizations and collectives, the efficiency increase of scientific management and research work, development of all science fields at levels of world standards, and the integration to world science. The aim of "e-science" is the wide application of ICT in scientific institutions, and the development of unified national scientific online infrastructure and information space [9].

AzScienceNet science-computer network provides the establishment of required information-communication infrastructure and the access to scientific-technical information and computation resources of scientific entities and organizations engaged in scientific activities via high-speed Internet network.

Due to absence of the common concept regarding the issues of reconstruction and development of scientific activity based on modern ICT at present, the work, conducted by organizations engaged in scientific activities, does not comply with contemporary requirements related to technical, economic and other problems [10]. Hence, the development and realization of 
"E-science" concept, based on world experience within "Electronic Azerbaijan" SP, is one of the exigent and topical issues occurred to scientists and experts.

"E-science" is an integral part of e-government, being formed within "Electronic Azerbaijan" SP. Its primary goal is the development of science in accordance with contemporary requirements, improvement of scientific administration, wide application of ICT in scientific institutions of the republic, the formation of a unified national scientific information space, the provision of information security, and thus, the achievement of close cooperation among scientific organizations, collectives and scientists, the efficiency increase of research works, the development of all fields of science at levels of modern world standards and the integration into world scientific space.

The "E-science" does not only envisage the ANAS institutions, but also the reconstruction of those with the application of ICT and the formation of unified online scientific infrastructure for the efficiency increase of performance of the country's scientific institutions.

The transparent, accurate and operative information regarding the top-priority directions of research works, ordered and financed scientific-research works, obtained results and so forth will accelerate the conduction of research works in progress, provide the mutual links between scientific organizations and scientists, facilitate the development of all scientific fields at levels of modern world standards, accelerate the integration of those into world sciences and as a result, will eliminate the digital backwardness.

The e-science project platform and infrastructure is contemplated to be established on the basis of AzScienceNet science-computer network.

It is to be mentioned that there is an emerging demand for the establishment of data processing centers formed on the basis of supercomputers for the solution of strategically important complex issues; these issues require large computational and memory resources, and emerge in government institutions and scientific-research institutes during the realization of the above mentioned "E-science" project, the evaluation processes of electronic signature and coding algorithms maintaining the information security of e-government, which is being formed and while providing high-speed Internet services to users.

At the same time, a substantial need has emerged for the realization of complex works towards the enhancement of AzScienceNet science-computer network infrastructure, reliable construction of security and monitoring system, the application of open grid, cloud computing, eduroam services and electronic document flow, the organization of video conference systems and the integration into corresponding scientific network institutions operating at international level and in other countries, in accordance with the requirements of "E-science" program.

The establishment of distributed multi-terminal information system service is of great importance. This system provides the information transmission to monitors located in entrances, lounges and conference halls of geographically distributed institutions and organizations. The management and information transmission to the monitors is operated from the single center.

Application fields of the system:

- Dissemination of corporate information (internal news, appeals of administration and etc.) of organizations and institutions;

- Dissemination of scientific novelties in different fields;

- Dissemination of report information and videos;

The establishment of multi-point video conference system is considered within AzScienceNet science-computer network in the near future. This system will comprise the institutes and organizations of ANAS, and higher education institutions. The created service will provide the online streaming of lectures on various science fields in conference halls of higher and scientific institutions of the republic via network.

The organization of online web-seminars in AzScienceNet science-computer network. Another service to be created in the near future is the organization of online web-seminars via the 
service network. This service will facilitate the access to "Informatics" subject lectures from home or work place for doctoral students and degree candidates. Tests are being held on this service.

AzScienceNet science-computer network also operates in the direction of establishment and development of international connections:

- Member of TERENA organization since 2011.

- Member of GEANT (Gigabit European Advanced Network Technology) Association since 2014.

\section{Conclusion}

AzScienceNet science-computer network plays a prominent role in information society building in Azerbaijan by maintaining the contemporary network services that are necessary for the solution of scientific studies, as well as scientific-practical and education issues conducted in ANAS institutes and organizations. Necessary potential exists for the enhancement of the activity of AzScienceNet science-computer network, the improvement of service quality and coverage, expansion of international relations, as well as the realization of prospects for determining targets towards the provision of new services. The efficient implementation of the potentials of AzScienceNet science-computer network is necessary for future development of information society and its important segment - the electronic science, in the country.

This work has been carried out with the financial assistance of Science Development Fund under the President of Republic of Azerbaijan - Grant № EIF-2014-9(24)-KETPL-14/02/1

\section{References}

1. https://www.terena.org

2. Alakbarov R.G. On the use policy of AzScienceNet network services // First Republican scientific-practical conference on Electronic Science Problems, 15-16 November, 2012, Baku, Azerbaijan, pp. 89-90.

3. Nabiyev B.R. On the monitoring system of information security in AzScienceNet network // "First Republican scientific-practical conference on Information Security Problems" dedicated to 90th anniversary of national leader of Azerbaijan Heydar Aliyev, 17-18 May, 2013, Baku, Azerbaijan.

4. Nabiyev B.R. The Formation of Requirement System for Critical Tasks from the point of view of Information Security // "First Republican scientific-practical conference on Information Security Problems" dedicated to 90th anniversary of national leader of Azerbaijan Heydar Aliyev, 17-18 May, 2013, Baku, Azerbaijan, p.128.

5. Alakbarov R.G. On security policy of AzScienceNet computer-science network // "First Republican scientific-practical conference on Information Security Problems" dedicated to 90th anniversary of national leader of Azerbaijan Heydar Aliyev, 17-18 May, 2013, Baku, Azerbaijan, pp. 126-127.

6. Alguliev R.M., Alekperov R.G. CLOUD COMPUTING: Modern state, problems and prospects. // Telecommunications and Radio Engineering. USA, 2013, DOI:10.1615 // TelecomRadEng. Number 3. vol. 72. i3.80. p. 255-266.

7. Marios D. Dikaiakos, George Pallis, Dimitrios Katsaros, Pankaj Mehra, Vakali Athena. Cloud Computing, Distributed Internet Computing for IT and Scientific Research // IEEE INTERNET COMPUTING - 2009. № 9. pp.10-13.

8. https://www.eduroam.org/index.php? $\mathrm{p}=$ europe

9. Alguliev R.M., Fataliyev T.Kh. Electronic science: goals, tasks and development prospects // I Republican scientific-practical conference on Electronic Science Problems, 15-16 November, 2012, Baku, Azerbaijan, pp.11-12.

10. Fataliyev T.Kh. The monitoring of application of information technologies in scientific activity // Express-information, "Information Technologies" press, 2010, Baku, 68 p. 